\title{
Action of a non-ionic detergent on chromatophores of Rhodopseudomonas spheroides
}

All photosynthetic pigments of the purple bacteria are located in submicroscopic structures, which have been named "chromatophores"1,2. Though the whole group of these organisms seem to possess only one type of bacteriochlorophyll, colloidal extracts of chromatophores from various strains show strikingly different absorption spectra in the near infrared. These differences have been attributed to binding of bacteriochlorophyll to different proteins or lipoproteins ${ }^{3}$, and some indirect evidence is available to support this hypothesis. Isolation of these still hypothetical pigment-protein complexes would be of great interest, if only to get an insight into the structural organization of these photoactive particles. However, the ease with which bacteriochlorophyll is removed from its carrier molecule, as evidenced by spectral changes, hampers the isolation by usual procedures.

We looked for a technique which would bring about fragmentation and, possibly, solubilization of these particles as a first step towards the isolation of the complexes. Using the nonionic detergent Triton X roo (alkylated aryl polyetheralcohol), we made the following promising observation.

Chromatophores of Rhodopseudononas spheroides were prepared by differential centrifugation

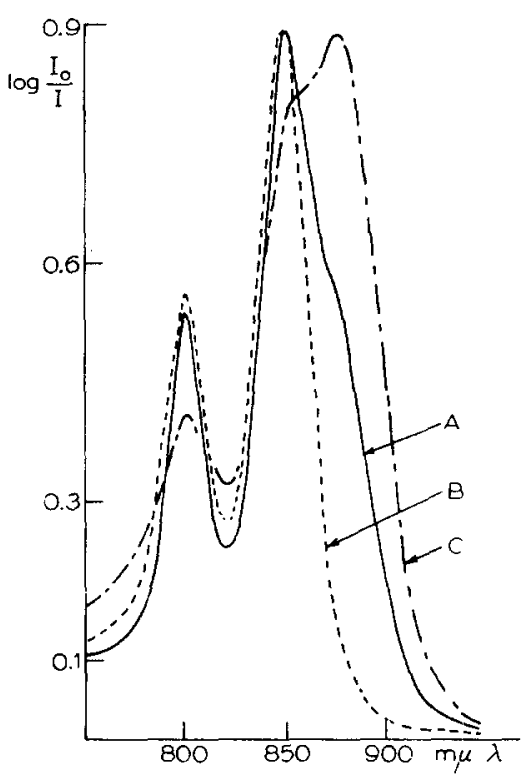
following sonic desintegration of the bacterial cells. combined fractions of "large" and "small" particles were used ${ }^{1,2}$. The absorption spectrum of suspensions of these particles shows two sharp peaks at about $800 \mathrm{~m} \mu$ and $850 \mathrm{~m} \mu$ and a slight but definite shoulder at about $880 \mathrm{~m} \mu$. When the particles were homogenized in o. I $M$ tris(hydroxymethyl)aminomethane, $\mathrm{pH} 8.5$, containing $0.5 \%$ detergent, and the suspension was centrifuged at $1_{44,000} \times g$ for $2 \mathrm{~h}$, a considerable a mount of pigmented material remained in solution. Examining the spectrum of this supernatant fraction, it appears that the absorption at $880 \mathrm{~m} \mu$ has completely disappeared (Fig. 1).

Fig. 1. Mbsorption spectra of suspensions of non-treated and detergent-treated chromatophores.

(iurve 1. Non-treated.

(irve 13. Detergent-treated, supernatant fraction.

(urve C. I)etergent-treated, sediment fraction.

Rehomogenizing the sediment in Tris buffer, on the other hand, resulted in a suspension, the main absorption of which is at 880 mul

Considering these observations, it is rather tempting to assume that the material responsible for the absorption at $880 \mathrm{~m} \mu$, which might be the long-sought pigment-protein complex, can be split off. I further suggestion is that the decreased absorption maxima at Boo nu and $8_{5} 0 \mathrm{~m} / \mu$ which remain in the spectrum of the sedimented material are due to contamination with particles which have not been fragmented, or only partially so, by detergent action.

Further studies along these lines are in progress and will be reported in greater detail at a later date.

C. TBRIL

Biophysical Research Group, Department of Physics of the State University, Utrecht (The Netherlands)

1 H. K. Schachman, A. B. PardeE AND R. Y. Stanier, frch. Biochem. Biophys., $38(1952) 345$.

$2 \mathrm{~J}$. W. Newton and G. A. Newton, Arch. Biochem. Biophys., 71 (19.57) 250.

3 E. C. WAssink, E. Katz AND R. DORRestein, Enzymologia, 7 (1939) 113 